\title{
Characterization of proton production and consumption associated with microbial metabolism
}

\author{
Karthikeyan Srinivasan ${ }^{1}$, Radhakrishnan Mahadevan ${ }^{1,2^{*}}$
}

\begin{abstract}
Background: Production or consumption of protons in growth medium during microbial metabolism plays an important role in determining the $\mathrm{pH}$ of the environment. Such $\mathrm{pH}$ changes resulting from microbial metabolism may influence the geochemical speciation of many elements in subsurface environments. Protons produced or consumed during microbial growth were measured by determining the amount of acid or base added in a $5 \mathrm{~L}$ batch bioreactor equipped with pH control for different species including Escherichia coli, Geobacter sulfurreducens, and Geobacter metallireducens.

Results: An in silico model was used to predict the proton secretion or consumption rates and the results were compared with the data. The data was found to confirm predictions of proton consumption during aerobic growth of E. coli with acetate as the carbon source. However, in contrast to proton consumption observed during aerobic growth of E. coli with acetate, proton secretion was observed during growth of Geobacter species with acetate as the donor and $\mathrm{Fe}(\mathrm{III})$ as the extracellular electron acceptor.

Conclusions: In this study, we have also shown that the final pH of the medium can be either acidic or basic depending on the choice of the electron acceptor for the same electron donor. In all cases, the in silico model could predict qualitatively the proton production/consumption rates obtained from the experimental data. Therefore, measurements of $\mathrm{pH}$ equivalents generated or consumed during growth can help characterize the microbial physiology further and can be valuable for optimizing practical applications such as microbial fuel cells, where growth associated $\mathrm{pH}$ changes can limit current generation rates.
\end{abstract}

\section{Background}

Geobacter species are well known for their metal reducing capabilities and are responsible for accelerating the bioremediation of radioactive and toxic metals in subsurface environments [1-3]. They are capable of anaerobic oxidation of organic contaminants with concomitant reduction of metals such as $\mathrm{Fe}(\mathrm{III})$ and other contaminants such as Uranium, and consequently are important for groundwater bioremediation [4-7]. Furthermore, Geobacter species are capable of direct electron transfer to an electrode motivating their use in microbial fuel cells [8]. The pure culture model of Geobacter sulfurreducens from Geobacteraceae family has been extensively studied in order to characterize its physiology and to

\footnotetext{
* Correspondence: krishna.mahadevan@utoronto.ca

'Department of Chemical Engineering and Applied Chemistry, University of Toronto, Toronto, Ontario, M5S3E5, Canada
}

determine the mechanisms associated with the extra-cellular electron transfer. Recently, several genome-wide studies have characterized the unique metabolic features of Geobacteraceae including the development of a genome-scale metabolic model of Geobacter sulfurreducens, the chemotaxis towards iron, and the synthesis of conductive pili [9-13]. The genome-based modeling revealed that, global proton balance was significantly different for Geobacter species, which rely on extra-cellular electron transfer to insoluble substrates, in comparison to aerobic organisms which reduce oxygen to water. Furthermore, improved understanding of the global proton balance in Geobacter species can provide insights on the physiology of other species capable of extra-cellular electron transfer such as Rhodoferax, Shewanella regardless of the mechanism of the electron transfer since

\section{() Biomed Central}

(c) 2010 Srinivasan and Mahadevan; licensee BioMed Central Ltd. This is an Open Access article distributed under the terms of the Creative Commons Attribution License (http://creativecommons.org/licenses/by/2.0), which permits unrestricted use, distribution, and reproduction in any medium, provided the original work is properly cited. 
protons are not consumed at the terminal electron accepting step in all cases.

Changes in the environmental conditions such as $\mathrm{pH}$, temperature, osmolarity, and electron donor availability can alter the trans-membrane $\mathrm{pH}$ gradient, total proton motive force and affect the internal $\mathrm{pH}$ of the cells as well as the energetics [14]. Hence, in order to maintain energy homeostasis, cells have to actively regulate the internal $\mathrm{pH}$ by secreting or consuming protons. The medium can act as a source/sink for protons depending on the substrates that are present. The characterization of this proton exchange can provide additional insights on the metabolism and physiology of less studied organisms such as Geobacteraceae that use extra-cellular electron transfer for energy generation.

Several in silico models have been constructed to describe and predict the intracellular metabolism at the genome-scale for many organisms including E. coli, S. cerevisiae, and B. subtilis [15-20]. Specifically, the constraint-based modeling approach has been used to study E. coli metabolism for over ten years $[21,22]$. These constraint-based models provide a framework to predict cellular physiology including growth and by-product formation across a range of growth environments [23]. Predictions of proton secretion/consumptions rates associated with $E$. coli grown under aerobic conditions in the presence of varying electron donors has been reported [24]. Consequently, the measurements of the proton secretion/consumption associated with the cellular growth and metabolism can be used to derive additional information on physiology that can be used to further validate the models.

The in silico analysis of Geobacter sulfurreducens metabolism revealed that differences in global intracellular proton balance can lead to lowered biomass yields during growth with extracellular electron acceptors such as $\mathrm{Fe}(\mathrm{III})$, relative to the growth with electron acceptors reduced in the cytosol, such as fumarate [25], highlighting the need for detailed analysis of the proton exchange associated with metabolism. One of the major concerns during high-density growth of $E$. coli on excess glucose under aerobic conditions is the formation of acidic byproducts [26-29]. Several studies have been carried out to determine the effect of fermentation conditions on accumulation of acetate and other by-products [26,30-33].

The bacterial cells grown in complex environment use the available substrate either preferentially or simultaneously depending on the growth condition. The metabolism of glucose and acetate in E. coli has been extensively investigated during the past 50 years [34] and are well characterized. Although dynamic models of growth on mixed substrates have been developed based on experimental data from substrate uptake rate and biomass production measurements [35-37], no previous experimental study, to our knowledge, measured the net production or consumption of protons in different environments, even though in the case of E. coli, modeling studies suggested that the direction of proton exchange was found to depend on the electron donor [24]. The scope of this work was to first confirm the previous model predictions of proton exchange for $E$. coli and subsequently, to measure the proton production or consumption during growth of Geobacter species on acetate with fumarate or ferric citrate and compare it with the in silico model predictions (Figure 1). Models that can predict the rate of proton secretion or consumption under a wide range of environmental conditions will be valuable in developing model-based approaches to the optimization of power production in microbial fuel cells and the in situ bioremediation of contaminated subsurface environments, where the effect of $\mathrm{pH}$ changes is critical.

\section{Results}

It has been shown previously that for Geobacter species, global proton balance has been shown to be critical in determining biomass yields during the respiration of extracellular electron acceptors. Here, we have investigated the relation between the growth environment and proton generation/consumption for E. coli, G. sulfurreducens and G. metallireducens. Specifically, we studied the variation in proton exchange as a function of the electron donor (glucose, acetate) for $E$. coli and the electron acceptor (fumarate/Fe(III) citrate) for G. sulfurreducens and G. metallireducens. The results from these experiments are detailed in the following sections.

\subsection{Analysis of Proton Production in E. coli}

Recent genome-scale metabolic models incorporate detailed charge and elemental balance, and consequently, the number of protons consumed or generated for every metabolic reaction is represented in the model. This feature allows the calculation of proton flux generated or consumed during growth in varied environments. Reed et al. [24] described the variation of proton secretion flux with the carbon source. Depending on the limiting substrate, the exchange of protons across the membrane can produce either basic or acid environment. For E. coli, during growth with acetate as electron donor, the external medium environment became basic and acid was added to maintain neutral $\mathrm{pH}$ as shown in Figure 2 (panels c \& d). The maximum observed $\mathrm{OD}_{550}$ $\mathrm{nm}$ value was 0.45 and substrate was completely consumed after $25 \mathrm{hrs}$. Similar experiment was carried out for growth of $E$. coli on glucose. However, in the case of growth with glucose, base was added in order to maintain circumneutral $\mathrm{pH}$ (Figures $2 \mathrm{a} \& 2 \mathrm{~b}$ ). The variations in proton generation with the electron donor are also 


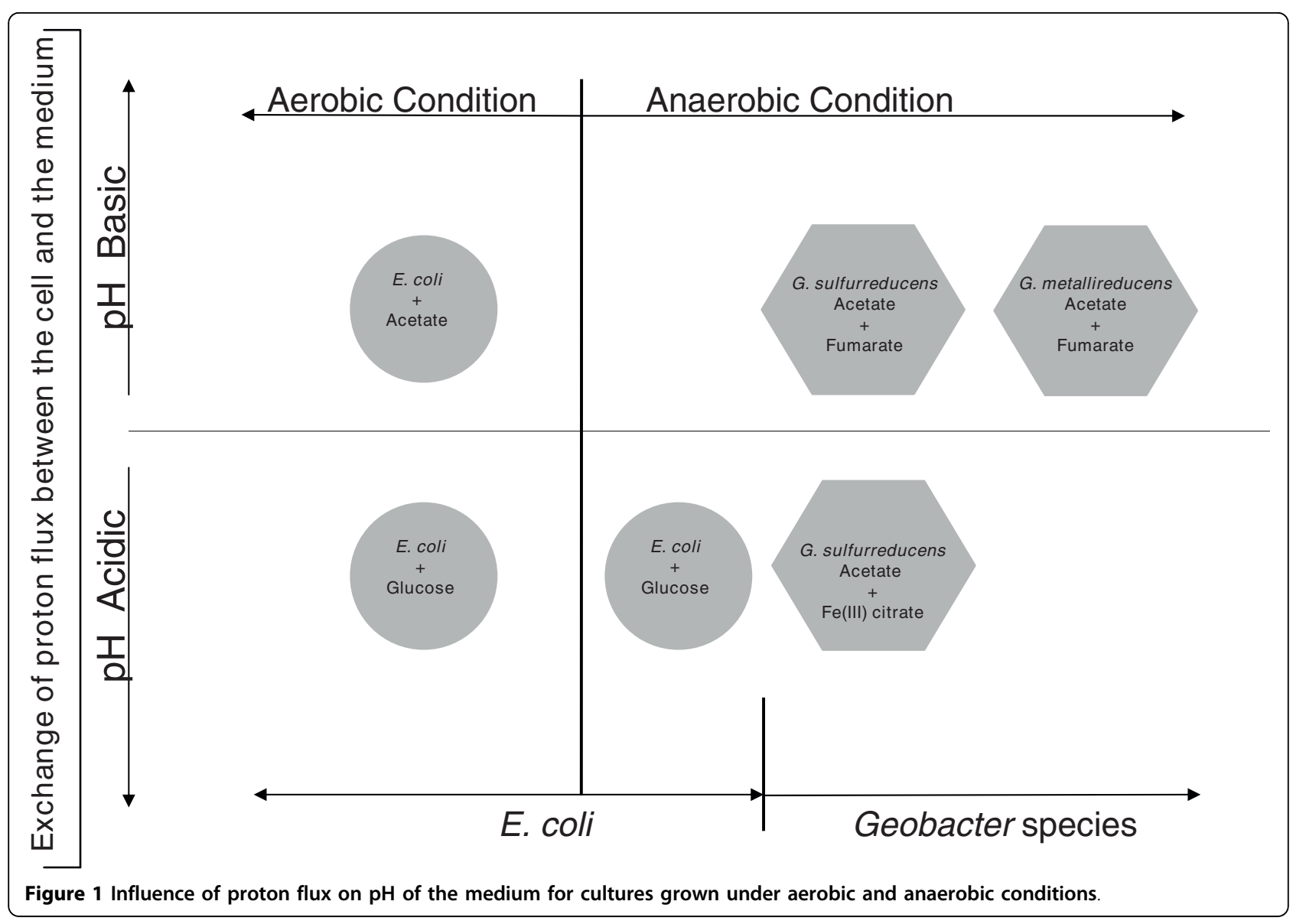

consistent with the reduced nature of glucose as compared to acetate. Thus, glucose oxidation resulted in generation of excess protons that are not consumed completely by the formation of water during the oxygen reduction. These excess protons are secreted into the medium along with other acid by-products resulting in an acidification of the medium forcing the addition of base to maintain a constant $\mathrm{pH}$. Table S1 (Additional file 1) shows the initial and final biomass concentrations and the amount of acid/base added for all of the studies in this report.

\subsection{Proton Production in Geobacter Species}

G. sulfurreducens and G. metallireducens containing the fumarate transporter [38], were grown in a batch bioreactor, in the absence of a buffer, with acetate $(10 \mathrm{mM})$ as electron donor and fumarate $(40 \mathrm{mM})$ as the sole electron acceptor as previously described [39]. In control experiment(s), the inoculum(s) was omitted to investigate changes in medium $\mathrm{pH}$. The medium $\mathrm{pH}$ remained neutral and there was no addition of either acid or base in all control experiments (data not shown).

Both the Geobacter strains showed a similar trend in the amount of acid added as compared to the aerobic growth of E. coli with acetate (Figure 3). The $\mathrm{pH}$ of the culture medium gradually increased and acid was added to maintain neutral $\mathrm{pH}$ as shown in Figures 3b \&3c. G. sulfurreducens and G. metallireducens obtained a maximum OD value of 0.37 and 0.42 respectively. Reed et al $[21,24]$ showed that by choosing different electron donors, the medium can be made either acidic or basic. In addition to the variation of the electron donors, we have also investigated the influence of electron acceptors on the medium $\mathrm{pH}$. Figure 4 shows the acetate consumption by G. sulfurreducens during growth in the presence of acetate $(10 \mathrm{mM})$ and $\mathrm{Fe}(\mathrm{III})$ citrate $(40 \mathrm{mM})$.

During the growth of G. sulfurreducens with $\mathrm{Fe}(\mathrm{III})$ citrate as sole electron acceptor, protons were produced by the cells. The cell growth was inferred indirectly by acetate oxidation and $\mathrm{Fe}(\mathrm{III})$ reduction since Optical Density (OD) measurements are not possible and cell counts lead to significant variances in the measurements. In control experiments, the acid addition started at the beginning and continued for $25 \mathrm{hrs}$ until volume of $10 \mathrm{ml}$ was dispensed into the bioreactor to maintain neutral $\mathrm{pH}$ (7.0), however reduction of $\mathrm{Fe}(\mathrm{III})$ was not observed. This observed increase in $\mathrm{pH}$ of the uninoculated medium upon $\mathrm{N}_{2}$ sparging can be explained by an inorganic reaction equilibria model (data not shown). In 

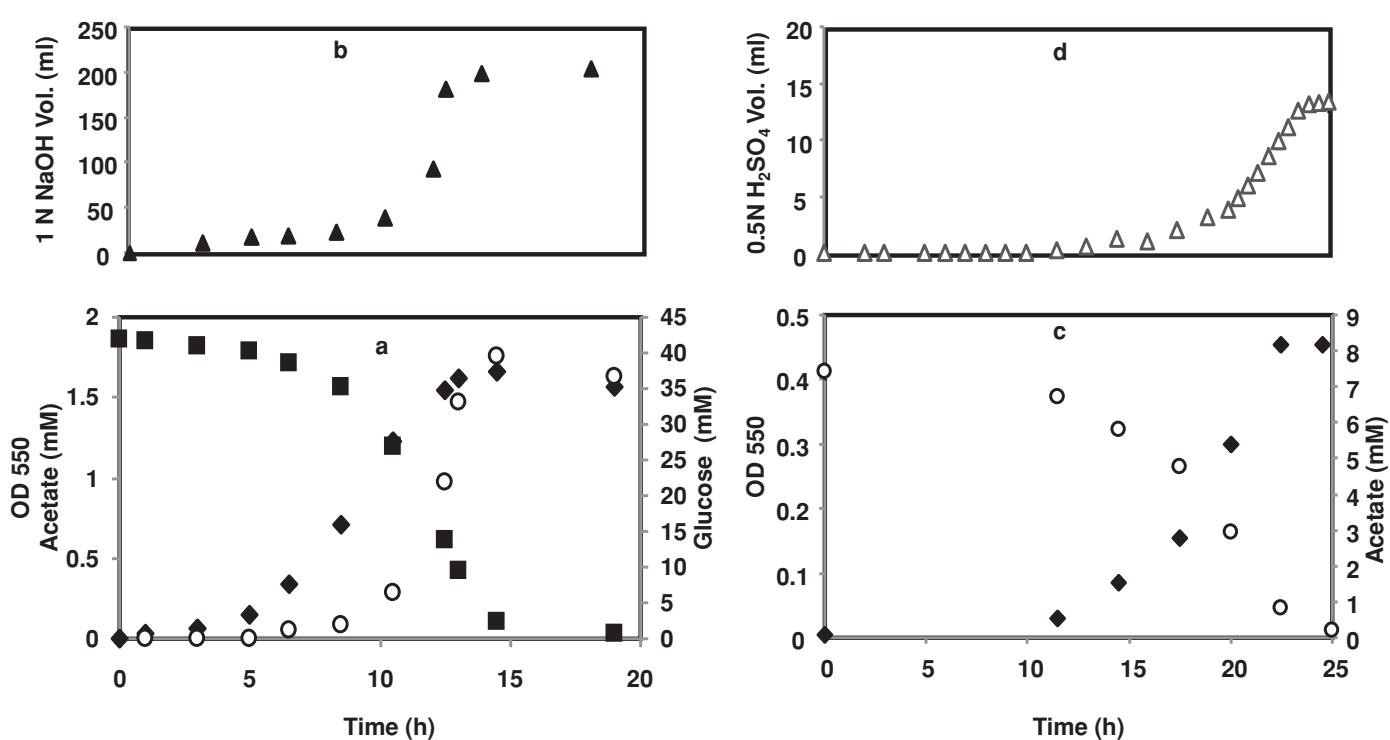

$\triangle$ OD O Acetate (mM) 口Glucose (mM)

Figure 2 Batch culture of E. coli W3110 with pH Control in a bioreactor in the absence of buffer. (a) growth with glucose; (b) base added; (c) growth with acetate; (d) acid added.

contrast, during the growth of Geobacter sulfurreducens, the medium was maintained at neutral $\mathrm{pH}$ without external addition of either acid or base. This can be attributed to the secretion of protons during the growth phase G. sulfurreducens as a result of cellular metabolism.

However, as $\mathrm{Fe}(\mathrm{III})$ was depleted at $25 \mathrm{hr}$, the cells reached stationary phase, consequently proton production associated with growth stopped and the acid had to be gradually added externally by the pump until it reached volume of $21 \mathrm{ml}$. The change in $\mathrm{pH}$ of the medium containing Fe(III) citrate in control experiments could be attributed to the potential release of hydroxyl ions from inorganic equilibrium reactions. The hydroxyl ions are reactive species, and will react immediately to form $\mathrm{Fe}(\mathrm{OH})_{3}$ which can precipitate in the solution. Similar results were reported by Francis and Dodge [40].

This study shows that proton exchange also depends on the choice of the electron acceptor. Specifically, for the case of the extracellular acceptors such as Fe(III),


Figure 3 Proton consumption by Geobacter species in the absence of bicarbonate with pH control. Batch culture of G. sulfurreducens with acetate and fumarate (a); acid added (b); batch culture of G. metallireducens (c); acid added (d). 

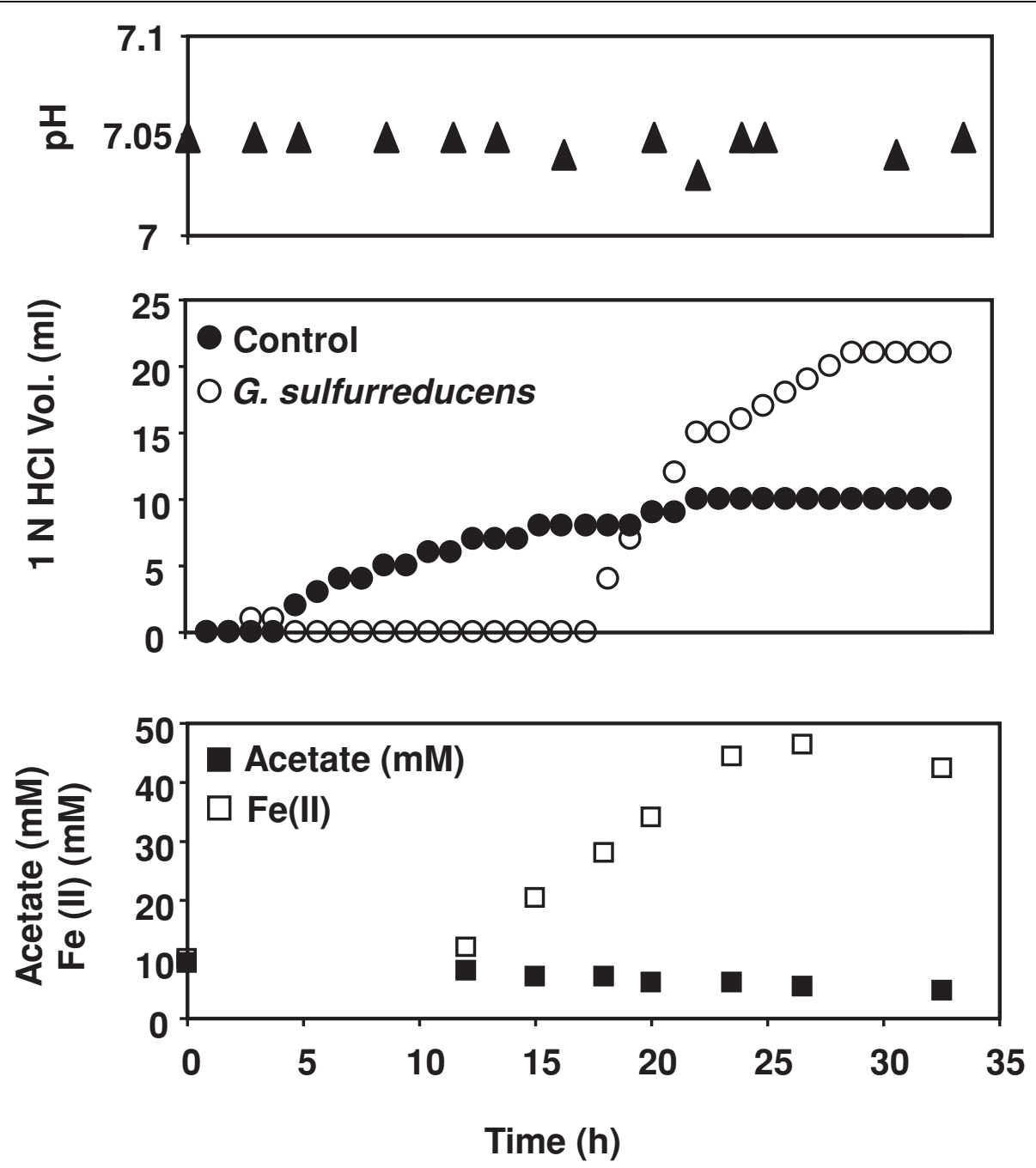

Figure 4 Proton production by Geobacter sulfurreducens in the absence of bicarbonate with acetate and ferric citrate.

there appears to be net production of protons. This result is consistent with the model predictions of proton secretion during $\mathrm{Fe}(\mathrm{III})$ reduction [25] and provides additional evidence to support the hypothesis, that the biomass yield of G. sulfurreducens in the presence of $\mathrm{Fe}$ (III) citrate as the electron acceptor is lower than fumarate due to the need to maintain global proton balance by exporting protons from the cell at the expense of ATP generation. The comparison of predicted and measured proton fluxes is presented in Figure 5. Here, the positive proton flux represents secretion and negative flux represents uptake. The model predictions of proton production are consistent with the data and are within the experimental error for E. coli cultures, where as for the Geobacter species the model predictions qualitatively predict proton consumption although the extent of the predicted proton consumption is higher than what is observed experimentally.

\section{Discussion}

Bacterial cells have to regulate the cytoplasmic $\mathrm{pH}$ to survive in the constantly changing environment as bacterial growth is dependent on substrate availability, as well as the redox potential and the $\mathrm{pH}$ of the medium. The regulation of internal $\mathrm{pH}$ involves proton export that requires energy in the form of ATP. The biochemical reactions in the cytoplasm associated with metabolism can lead to a net proton production or consumption. The variations in proton concentration in the cytoplasm during growth, can affect the kinetics and the thermodynamic feasibility of biochemical reactions necessitating active regulation of $\mathrm{pH}$. The energetic cost of $\mathrm{pH}$ regulation via exporting protons associated with metabolism can impact the biomass yield of the organism and the extent of this effect can vary with the environment.

For example, in E. coli grown with glucose as the electron donor, organic acids released during growth greatly 


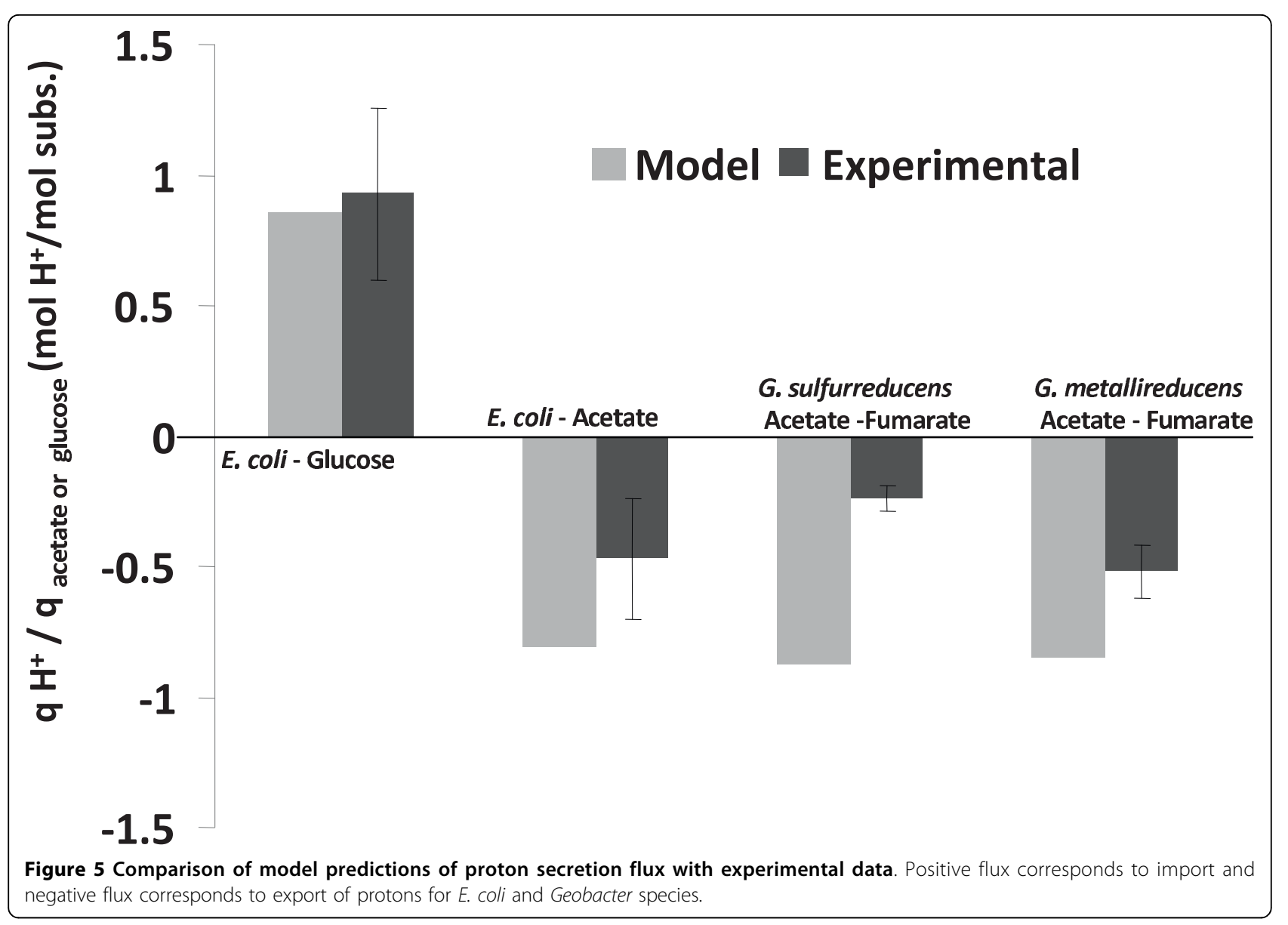

contribute to changes in $\mathrm{pH}$ of the medium. Previous studies [41-43] have shown that changes in $\mathrm{pH}$ of the culture medium affects the growth of microorganism. However, measurement of such $\mathrm{pH}$ changes can be used to analyze the metabolic state of the cells. Previously, changes in $\mathrm{pH}$ have been used to identify the onset of product synthesis using on-line parameter estimation in fermentation process San et al [44]. More recently, the in silico model by Reed et al [24] predicted the variation of proton secretion flux for $E$. coli with different electron donors. In this study, we have shown that the in silico model predictions were consistent with experimentally observed proton production or consumption in 1 ) cultures of $E$. coli grown aerobically on different electron donors, and 2) Geobacter species grown anaerobically on acetate with different electron acceptors.

During aerobic growth, intracellular protons along with electrons transferred from the electron transport chain combine with oxygen resulting in the formation of water as well as removal of intracellular protons. In contrast, during anaerobic growth with metals, the protons generated during substrate oxidation cannot be removed at the terminal electron accepting step. Consequently, proton generation profile during anaerobic growth will be markedly different from aerobic growth in similar conditions. In Geobacter species, acetate oxidation is coupled with reduction of fumarate which is the terminal electron acceptor. Biomass yield of G. sulfurreducens during acetate oxidation with fumarate as the electron acceptor is higher than the corresponding yield during Fe(III) reduction. This has been attributed to the differences in proton generation associated with metabolism, since during Fe(III) reduction, protons are generated and there is a net proton efflux that consumes energy. During the reduction of soluble acceptors such as fumarate, protons are consumed at the terminal electron accepting step resulting in a net proton uptake. In this study, during Fe(III) reduction, we observed a net production of protons, whereas, we found that during fumarate reduction acid was added to maintain $\mathrm{pH}$ balance indicating proton consumption.

The predicted proton uptake agreed with the measured acid addition for E. coli grown on glucose. However, for all other cases model predicted higher proton consumption by the cells. One reason for this discrepancy could be the incorrect representation of protons 
that are consumed during biomass production. Another factor could be either the bicarbonate produced during growth of $E$. coli that can buffer some of the $\mathrm{pH}$ changes experimentally or the production of organic acids that are not represented in the model. Yet another factor could be the uptake of $\mathrm{NH}_{4}{ }^{+}$followed by proton extrusion observed for bacteria and fungi [45-47]. While these mechanisms might explain the discrepancies for $E$. coli, it is important to note that $\mathrm{CO}_{2}$ is also consumed by G. sulfurreducens and acids cannot be secreted during acetate oxidation. Hence, the factors that contribute to proton production during growth of Geobacter species needs to be further elucidated. These effects are not incorporated in the current stoichiometric model which does not include the acid/base equilibrium reactions in the reactor. In addition, since the proton exchange flux was calculated based on the acid/base added during batch growth experiments, errors in the measurements could also lead to additional discrepancy between the model and the data.

\section{Conclusion}

The results in this study clearly highlight the ability of the genome-scale models that incorporate detailed proton balanced biochemical reactions to predict, albeit qualitatively, the proton exchange rates and other aspects of physiology. Future research in this area would extend the scope of genome-scale models by including detailed inorganic equilibria reactions to accurately represent the abiotic reactions that can consume or produce protons in the medium. In order to effectively incorporate the abiotic reactions in the model, additional experimental measurements such as the $\mathrm{CO}_{2}$ production/consumption rate along with $\mathrm{NH}_{4}$ consumption rate will be required. Such an integrated description will be valuable in practical applications such as the in situ bioremediation or microbial fuel cells, where changes in environmental $\mathrm{pH}$ would greatly affect the respiration and metabolism. Therefore, models that can predict the rate of proton secretion or consumption under a wide range of environmental conditions will be valuable in predicting the growth physiology as well as the extent of respiration and for prioritizing strategies for bioremediation of contaminated subsurface environments and optimization of power production in microbial fuel cells.

\section{Methods}

\subsection{Strains and Medium Composition}

The bacterial strains used were E. coli W3110, G. sulfurreducens (DL1), and G. metallireducens. The cultures of E. coli were grown on a defined medium containing mineral salts as described by Causey et al[48] and maintained at $37^{\circ} \mathrm{C}$. G. sulfurreducens and G. metallireducens were cultivated anaerobically at $30^{\circ} \mathrm{C}$ in a freshwater fumarate medium as previously described by EsteveNunez et al[39]

\subsection{Batch Culture}

A fully instrumented Minifors bioreactor was used for fermentation. The impeller speed was maintained constant at $200 \mathrm{RPM}$. The temperature was maintained at $30^{\circ} \mathrm{C}$ and $37^{\circ} \mathrm{C}$ for Geobacter strains and E. coli respectively. The $\mathrm{pH}$ was adjusted to 7.0 by automatic addition of equimolar solution of $2 \mathrm{~N} \mathrm{HCL}$ or $0.5 \mathrm{~N} \mathrm{H}_{2} \mathrm{SO}_{4}$ or 1 $\mathrm{M} \mathrm{NaOH}$. The electron donor for Geobacter species was acetate, supplied in the form of sodium acetate (10 $\mathrm{mM})$. The culture media was constantly sparged with 100\% Nitrogen for Geobacter strains and compressed air for $E$. coli respectively. For $E$. coli, either glucose (50 $\mathrm{mM})$ or acetate $(10 \mathrm{mM})$ was used as substrate. The working volume of the bioreactor for cultivation was 2.2L. In both cases, the phosphate and carbonate salts that provide buffering capacity was not included in the medium as the $\mathrm{pH}$ in the bioreactor was being controlled through the addition of acid or base via an external feedback control loop. The inoculum for batch cultivation was prepared in shake flask by growing the culture either on glucose or acetate for $E$. coli under aerobic conditions. Geobacter strain(s) were grown in a stationary incubator at $30^{\circ} \mathrm{C}$. Culture samples were taken at regular time intervals and stored at $-20^{\circ} \mathrm{C}$ for HPLC analysis.

\subsection{Analytical Methods}

The concentrations of organic acids and glucose in the culture samples was measured by Dionex HPLC equipped with UV detector, Refractive Index $(210 \mathrm{~nm})$ and Bio-Rad Aminex HPX-87H column. The cell growth was monitored by optical density measurements, using a spectrophotometer at $\mathrm{OD}_{550 \mathrm{~nm}}$ and $\mathrm{OD}_{600 \mathrm{~nm}}$ for E. coli and Geobacter species respectively. The cell mass is estimated for $E$. coli as $1.0 \mathrm{OD}_{550 \mathrm{~nm}}$ is equivalent to $0.33 \mathrm{~g}$ dry cell weight/litre [48] and for Geobacter as $1.0 \mathrm{OD}_{600}$ is equivalent to $0.47 \mathrm{~g}$ dry cell weight/litre. Fe(III) reduction was monitored by measuring the amount of $\mathrm{Fe}(\mathrm{II})$ formed using the Ferrozine assay as reported in [4].

\subsection{Simulations}

The experimental values were compared with the in silico models. For E. coli, the results were compared with the model iJR904 predictions using the COBRA tool box described by Becker et al. [49], while for the Geobacter species, the model presented in Mahadevan et al. [25] and Sun et al. [50] was used to simulate the metabolism. All simulations were carried out using the constraint-based modeling approach described in Becker et al. [49].

In this approach, the known biochemical reactions are inferred from the genome annotation and assembled into a genome-scale metabolic network. The 
stoichiometry of resulting reaction list is represented by a matrix (S), whose columns correspond to the reactions in the network and the rows correspond to the metabolites in the network. A set of linear constraints relating the fluxes (v) are derived based on the assumption that the metabolite pools have to be balanced during cell growth as there is no net production or consumption of metabolites. These linear equations derived from the genome-scale network are typically undetermined as there are more variables than equations resulting in plurality of solutions for the flux through the metabolic network. Hence, in order to determine a sole flux vector, a linear optimization problem to maximize a cellular objective such as the growth rate (represented by the objective weight vector, $c$ ) in the presence of bound constraints on the fluxes (v) is formulated as show below.

$$
\begin{aligned}
& \operatorname{Max} c^{T} v \\
& S v=0 \\
& l b<v<u b
\end{aligned}
$$

\subsection{Determination of specific rate of proton exchange (qH $\left.{ }^{+}\right)$}

The $\mathrm{pH}$ in the bioreactor is maintained constant by addition of acid or base. Therefore, one can calculate the total amount of protons consumed or produced in the medium from the total amount of acid or base added. If protons are consumed as a result of cellular metabolism, then the $\mathrm{pH}$ in the medium will increase as the proton concentration decreases and on the contrary, if protons are secreted into the medium as a result of metabolism, the $\mathrm{pH}$ in the medium will decrease as proton concentration increases. In the absence of a buffer, the net protons produced or consumed can then be related to the rate of production using the following equation

$$
\frac{V d\left[H^{+}\right] \text {medium }}{d t}=q_{H} X V \pm F N
$$

Where $\mathrm{X}$ is Biomass Concentration (gdw/l), $\mathrm{N}$ is Normality of base or acid added, $\mathrm{V}$ is Volume of Medium (l), $\mathrm{F}$ is the flow rate of acid or base added (l/hr), and $\mathrm{q}_{\mathrm{H}}$ is the proton exchange rate ( $\mathrm{mol} / \mathrm{gdw} \mathrm{hr}$ ). Since $\mathrm{X}$ varies with time, even though the $\mathrm{pH}$ is constant, we first obtain the proton yield during the growth phase rather than the absolute rate of proton production $\left(\mathrm{q}_{\mathrm{H}}\right)$.

$$
q_{H}=\frac{\mu}{Y_{X / H}}
$$

During balanced growth, the rate of proton production is directly proportional to specific growth rate described by Larrson et al. [51] and Ayaaki et al. [52]

$$
Y_{X / H}=\frac{\text { Net Protons Produced/Consumed }}{\text { Net Biomass Produced }}=\frac{\int_{t_{0}}^{t_{f}} F(t) N d t}{V \Delta X}
$$

Where $Y_{X / H}$ is the yield of protons produced per gram of biomass (moles/gdw), $\Delta \mathrm{X}$ is the change in biomass concentration, $t_{o}, t_{f}$ are the times corresponding to the beginning and the end of the growth phase.

Additional file 1: Table S1. Initial and final biomass concentrations and the amount of acid/base added.

Click here for file

[ http://www.biomedcentral.com/content/supplementary/1472-6750-10-2S1.PPT]

\section{Acknowledgements}

This research was supported by funding from Office of Science (BER), U.S Department of Energy, Cooperative Agreement No. DE-FC02-02ER63446 through the Genomics:GtL Program. We would also like to acknowledge Prof. Derek Lovley for donating the Geobacter strains and the protocols as well as for valuable discussions. Authors also acknowledge funding for research infrastructure from the Canadian Foundation of Innovation and the Ontario Ministry of Research and Innovation.

\section{Author details}

'Department of Chemical Engineering and Applied Chemistry, University of Toronto, Toronto, Ontario, M5S3E5, Canada. ${ }^{2}$ Institute of Biomaterials and Biomedical Engineering, University of Toronto, Ontario, M5S3G9, Canada.

\section{Authors' contributions}

KS designed and performed the experiments, interpreted data and wrote the paper, RM conceived of the study, interpreted data and wrote the paper. All authors read and approved the final manuscript.

Received: 27 May 2009

Accepted: 20 January 2010 Published: 20 January 2010

\section{References}

1. Anderson RT, Vrionis HA, Ortiz-Bernad I, Resch CT, Long PE, Dayvault R, Karp K, Marutzky S, Metzler DR, Peacock A, et al: Stimulating the in situ activity of Geobacter species to remove uranium from the groundwater of a uranium-contaminated aquifer. Applied and Environmental Microbiology 2003, 69(10):5884-5891.

2. Lovley DR: Cleaning up with genomics: Applying molecular biology to bioremediation. Nature Reviews Microbiology 2003, 1(1):35-44.

3. Lovley DR, Phillips EJP, Gorby YA, Landa ER: Microbial reduction of uranium. Nature 1991, 350(6317):413-416.

4. Lovley DR, Baedecker MJ, Lonergan DJ, Cozzarelli IM, Phillips EJP, Siegel DI: Oxidation of aromatic contaminants coupled to microbial iron reduction. Nature 1989, 339(6222):297-300.

5. Lovley DR: Potential for anaerobic bioremediation of BTEX in petroleumcontaminated aquifers. Journal of Industrial Microbiology \& Biotechnology 1997, 18(2-3):75-81.

6. Lovley DR, Lonergan DJ: Anaerobic oxidation of toulene, phenol, and para-cresol by the dissimilatory iron-reduction organism, GS 15. Applied and Environmental Microbiology 1990, 56(6):1858-1864.

7. Lovley DR: Dissimilatory fe(III) and Mn(IV) reduction. Microbiological Reviews 1991, 55(2):259-287. 
8. Bond DR, Lovley DR: Electricity production by Geobacter sulfurreducens attached to electrodes. Applied and Environmental Microbiology 2003, 69(3):1548-1555

9. Caccavo F, Lonergan DJ, Lovley DR, Davis M, Stolz JF, Mclnerney MJ: Geobacter sulfurreducens sp. nov., a hydrogen- and acetate-oxidizing dissimilatory metal-reducing microorganism. Applied and Environmental Microbiology 1994, 60(10):3752-3759.

10. Coppi MV, Leang C, Sandler SJ, Lovley DR: Development of a genetic system for Geobacter sulfurreducens. Applied and Environmental Microbiology 2001, 67(7):3180-3187.

11. Methe BA, Nelson KE, Eisen JA, Paulsen IT, Nelson W, Heidelberg JF, Wu D, Wu M, Ward N, Beanan MJ, et al: Genome of Geobacter sulfurreducens: Metal reduction in subsurface environments. Science 2003, 302(5652):1967-1969.

12. Methe BA, Webster J, Nevin K, Butler J, Lovley DR: DNA microarray analysis of nitrogen fixation and $\mathrm{Fe}$ (III) reduction in Geobacter sulfurreducens. Applied and Environmental Microbiology 2005, 71(5):2530-2538.

13. Nunez C, Esteve-Nunez A, Giometti C, Tollaksen S, Khare T, Lin W, Lovley DR, Methe BA: DNA microarray and proteomic analyses of the RpoS regulon in Geobacter sulfurreducens. Journal of Bacteriology 2006, 188(8):2792-2800.

14. Repaske DR, Adler J: Change in intracellular pH of Escherichia coli mediates the chemotactic response to certain attractants and repellents. Journal of Bacteriology 1981, 145(3):1196-1208

15. Duarte NC, Herrgard MJ, Palsson BO: Reconstruction and validation of Saccharomyces cerevisiae iND750, a fully compartmentalized genomescale metabolic model. Genome Research 2004, 14(7):1298-1309.

16. Oh YK, Palsson BO, Park SM, Schilling CH, Mahadevan R: Genome-scale reconstruction of metabolic network in Bacillus subtilis based on highthroughput phenotyping and gene essentiality data. Journal of Biological Chemistry 2007, 282:28791-28799.

17. Becker SA, Palsson BO: Genome-scale reconstruction of the metabolic network in Staphylococcus aureus N315: an initial draft to the twodimensional annotation. Bmc Microbiology 2005, 7(5):8

18. Famili I, Forster J, Nielson J, Palsson BO: Saccharomyces cerevisiae phenotypes can be predicted by using constraint-based analysis of a genome-scale reconstructed metabolic network. Proceedings of the National Academy of Sciences of the United States of America 2003, 100(23):13134-13139.

19. Forster J, Famili I, Fu P, Palsson BO, Nielsen J: Genome-scale reconstruction of the Saccharomyces cerevisiae metabolic network. Genome Research 2003, 13(2):244-253.

20. Reed JL, Palsson BO: Genome-scale in silico models of $E$. coli have multiple equivalent phenotypic states: Assessment of correlated reaction subsets that comprise network states. Genome Research 2004, 14(9):1797-1805.

21. Reed JL, Palsson BO: Thirteen years of building constraint-based in silico models of Escherichia coli. Journal of Bacteriology 2003, 185(9):2692-2699.

22. Feist AM, Palsson BO: The growing scope of applications of genome-scale metabolic reconstructions using Escherichia coli. Nature Biotechnology 2008, 26(6):659-667.

23. Palsson B: The challenges of in silico biology. Nature Biotechnology 2000, 18(11):1147-1150.

24. Reed JL, Vo TD, Schilling CH, Palsson BO: An expanded genome-scale model of Escherichia coli K-12 (iJR904 GSM/GPR). Genome Biology 2003, 4(9).

25. Mahadevan R, Bond DR, Butler JE, Esteve-Nunez A, Coppi MV, Palsson BO, Schilling $\mathrm{CH}$, Lovley DR: Characterization of metabolism in the $\mathrm{Fe}(\mathrm{III})-$ reducing organism Geobacter sulfurreducens by constraint-based modeling. Applied and Environmental Microbiology 2006, 72(2):1558-1568.

26. Brown TDK, Jonesmortimer MC, Kornberg HL: The enzymatic interconversion of acetate and acetyl-coenzyme A in Escherichia coli. Journal of General Microbiology 1977, 102(OCT):327-336.

27. Phue JN, Noronha SB, Bhattacharyya R, Wolfe AJ, Shiloach J: Glucose metabolism at high density growth of $E$. coli B and E. coli K: Differences in metabolic pathways are responsible for efficient glucose utilization in E. coli B as determined by microarrays and northern blot analyses (vol 90, pg 805, 2005). Biotechnology and Bioengineering 2005, 91(5):649-649.

28. Reiling HE, Laurila $H$, Fiechter A: Mass culture of Escherichia coli: Medium development for low and high density cultivation of Escherichia coli B/r in minimal and complex media. Journal of Biotechnology 1985, 2(34):191-206.

29. Rinas U, Krackehelm HA, Schugerl K: Glucose as a substrate in recombinant strain fermentation technology. By-product formation, degradation and intracellular accumulation of recombinant protein Applied Microbiology and Biotechnology 1989, 31(2):163-167.

30. Doelle HW, Ewings KN, Hollywood NW: Regulation of glucose metabolism in bacterial systems. Adv Biochem Eng 1982, 23:1-35.

31. Landwall $P$, Holme T: Influence of glucose and dissolved oxygen concentrations on yields of Escherichia coli B in dialysis culture. Journal of General Microbiology 1977, 103(DEC):353-358.

32. Smirnova GV, Oktyabrskii ON: Effect of the activity of primary proton pumps on the growth of Escherichia coli in the presence of acetate. Microbiology 1988, 57(4):446-451.

33. Anderson KW, Grulke E, Gerhardt P: Microfiltration culture process for enhanced production of rDNA receptor Cells of Escherichia coli. BioTechnology 1984, 2(10):891-896

34. Cozzone AJ: Regulation of acetate metabolism by protein phosphorylation in enteric bacteria. Annual Review of Microbiology 1998, 52:127-164.

35. Kovarova-Kovar K, Egli T: Growth kinetics of suspended microbial cells: From single-substrate-controlled growth to mixed-substrate kinetics. Microbiology and Molecular Biology Reviews 1998, 62(3):646.

36. Zinn $M$, Witholt B, Egli T: Dual nutrient limited growth: models, experimental observations, and applications. Journal of Biotechnology 2004, 113(1-3):263-279

37. Beg OK, Vazquez A, Ernst J, de Menezes MA, Bar-Joseph Z, Barabasi AL, Oltvai ZN: Intracellular crowding defines the mode and sequence of substrate uptake by Escherichia coli and constrains its metabolic activity. Proceedings of the National Academy of Sciences of the United States of America 2007, 104(31):12663-12668.

38. Butler JE, Glaven RH, Esteve-Nunez A, Nunez C, Shelobolina ES, Bond DR, Lovley DR: Genetic characterization of a single bifunctional enzyme for fumarate reduction and succinate oxidation in Geobacter sulfurreducens and engineering of fumarate reduction in Geobacter metallireducens. Journal of Bacteriology 2006, 188(2):450-455.

39. Esteve-Nunez A, Rothermich M, Sharma M, Lovley D: Growth of Geobacter sulfurreducens under nutrient-limiting conditions in continuous culture. Environmental Microbiology 2005, 7(5):641-648.

40. Francis AJ, Dodge CJ: Influence of Complex Structure on the Biodegradation of Iron-Citrate Complexes. Applied and Environmental Microbiology 1993, 59(1):109-113.

41. Kotyk A: Proton Extrusion in Yeast. Methods in Enzymology 1989, 174:592-603.

42. Sigler K. Hofer M: Mechamisms of acid extrusion in Yeast. Biochimica Et Biophysica Acta 1991, 1071(4):375-391.

43. Castrillo Jl, Demiquel I, Ugalde UO: Proton production and consumption pathways in yeast metabolism. A chemostat culture analysis. Yeast 1995, 11(14):1353-1365.

44. San KY, Stephanopoulos G: Studies on on-line bioreactor identification. IV Utilization of $\mathrm{pH}$ measurements for product estimation. Biotechnology and Bioengineering 1984, 26(10):1209-1218.

45. Sigler K, Knotkova A, Paca J, Wurst M: Extrusion of metabolites from baker's yeast during glucose-induced acidification. Folia Microbiologica 1980, 25(4):311-317.

46. Sigler K, Kotyk A, Knotkova A, Opekarova M: Processes involved in the creation of buffering capacity and in substrate-induced proton extrusion in the yeast Saccharomyces cerevisiae. Biochimica Et Biophysica Acta 1981, 643(3):583-592.

47. Roos $W$, Luckner $M$ : Relationships between proton extrusion and fluxes of ammonium ions and organic acids in Penicillium cyclopium. Journal of General Microbiology 1984, 130(APR):1007-1014.

48. Causey TB, Zhou S, Shanmugam KT, Ingram LO: Engineering the metabolism of Escherichia coli W3110 for the conversion of sugar to redox-neutral and oxidized products: Homoacetate production. Proceedings of the National Academy of Sciences of the United States of America 2003, 100(3):825-832

49. Becker SA, Feist AM, Mo ML, Hannum G, Palsson BO, Herrgard MJ: Quantitative prediction of cellular metabolism with constraint-based models: the COBRA Toolbox. Nature Protocols 2007, 2:727-738. 
50. Sun J, Sayyar B, Butler JE, Pharkya P, Fahland TR, Famili I, Schilling CH, Lovley DR, Mahadevan R: Genome-scale constraint-based modeling of Geobacter metallireducens. BMC Systems Biology 2009, 3, doi:10.1186/17520509-1183-1115.

51. Larsson G, Enfors SO, Pham H: The pH-Auxostat as a Tool for Studying Microbial Dynamics in Continuous Fermentation. Biotechnology and Bioengineering 1990, 36(3):224-232.

52. Ishizaki A, Tripetchkul S, Tonokawa M, Shi ZP, Shimizu K: pH-mediated control methods for continuous ethanol fermentation using Zymomonas mobilis. Journal of Fermentation and Bioengineering 1994, 77(5):541-547.

doi:10.1186/1472-6750-10-2

Cite this article as: Srinivasan and Mahadevan: Characterization of proton production and consumption associated with microbial metabolism. BMC Biotechnology 2010 10:2

Submit your next manuscript to BioMed Central and take full advantage of:

- Convenient online submission

- Thorough peer review

- No space constraints or color figure charges

- Immediate publication on acceptance

- Inclusion in PubMed, CAS, Scopus and Google Scholar

- Research which is freely available for redistribution

Submit your manuscript at www.biomedcentral.com/submit 